\title{
Evaluation of the Impact of Quality Variations in a Veterinary Pharmaceutical Industry in the Outsourcing of Productive Processes
}

Clara Ludmilla Pereira Brasil Comunello ${ }^{1}$ - Universidade Federal de São Paulo Alcides Barrichello - Universidade Presbiteriana Mackenzie Rogerio Scabim Morano ${ }^{3}$ - Universidade Federal de São Paulo

\section{RESUMO}

Qualquer processo, seja ele produtivo ou não, é suscetível a falhas e estas podem gerar consequências nos produtos finais. Na indústria farmacêutica veterinária a gestão destas falhas, além de ser uma das demandas do sistema de qualidade, é uma necessidade legal, verificada por auditorias de agências regulatórias. Assim, a gestão das não conformidades apresenta grande importância para melhoria contínua. Atrelado a isso, verifica-se nos últimos anos a tendência de aumento da prática de terceirização da produção de medicamentos veterinários em vista das vantagens financeiras envolvidas. Com essa mudança no processo produtivo, identificam-se dificuldades relacionadas à avaliação do impacto financeiro destes desvios para as empresas contratantes. Em vista disso, este trabalho, por meio de um estudo de caso, teve como objetivo o levantamento de desvios de manufatura, suas causas raiz e ações corretivas determinadas pela empresa terceira, e os custos envolvidos com essas falhas para a empresa contratante. Com essas informações verificou-se oportunidades de melhorias do processo, visando destinar investimentos de forma mais assertiva.

Palavras-chave: Terceirização. Modelo de terceirização. Indústria farmacêutica veterinária. Avaliação do impacto financeiro.

\section{ABSTRACT}

Any process, whether productive or not, is susceptible to failures, and these may or may not have negative consequences on the final products. In the veterinary pharmaceutical industry, the management of these failures, as well as being one of the demands of the quality system, is also a legal necessity, which is verified in audits by all the regulatory agencies. Therefore, the management of nonconformities is of great importance for continuous improvement. Linked to this, there has been a trend in recent years to increase the practice of outsourcing the production of veterinary drugs given the financial advantages this brings. With this change in the production process, difficulties related to the evaluation of the financial impact of these deviations for the contracting company have been identified. In view of this, this case studies the variations in manufacturing, and the root causes and corrective actions determined by the contracted company. The costs entailed with these failures were also examined. With this information, opportunities for improvement of the process were identified, with a view to allocating the investments more assertively.

Keywords: Outsourcing. Model. Veterinary pharmaceutical industry. Financial impact assessment.

1. claraludmilla@gmail.com; 2. alcidesbarrichel@uol.com.br; 3. Rua Prof. Artur Riedel, n² 275 - Jd. Eldorado - CEP: $09972-270$ Diadema-SP,r.morano@uol.com.br.

COMUNELLO, C.L.P.B.; BARRICHELLO, A.; MORANO, R.S. Avaliação do impacto de desvios de qualidade em uma indústria farmacêutica veterinária na terceirização de processos produtivos. GEPROS. Gestão da Produção, Operações e Sistemas, v. 14, n. 5, p. $215-238,2019$.
Editor Responsável: Prof. Dr. Hermes Moretti Ribeiro da Silva 
Avaliação do impacto de desvios de qualidade em uma indústria farmacêutica veterinária na terceirização de processos produtivos

\section{INTRODUÇÃO}

O mercado farmacêutico veterinário mundial atingiu um total de US\$ 30 bilhões em 2016 (SIDAN, 2018), sendo Estados Unidos e Brasil os dois maiores produtores de proteína animal e os maiores mercados veterinários do mundo. Situação semelhante de crescimento se verifica no mercado farmacêutico veterinário brasileiro nos últimos anos. Isso se deve ao fato do segmento de animais de produção; que inclui ruminantes, aves, suínos e equinos; representar mais de $85 \%$ do mercado do país. O Brasil possui o maior rebanho bovino comercial e o segundo maior rebanho total do mundo. Com isso, o crescimento do mercado de saúde animal brasileiro estimula a profissionalização da atividade pecuária no país, trazendo maior preocupação com o cuidado sanitário do rebanho (FERNANDES et al., 2013).

Neste contexto, o Brasil está cada vez mais estruturado em relação às regulamentações e normas sanitárias para fabricação de medicamentos veterinários, alinhando-se cada vez mais aos padrões internacionais. É de extrema importância que os medicamentos sejam fabricados dentro de padrões e especificações de qualidade que não atendam somente às exigências locais, demandando esforço por parte das empresas em atender e se adequar a tais requisitos, e contribuindo para aumento do já elevado custo de produção (ROCHA; GALENDE, 2014).

Com o avanço da globalização, os clientes tornaram-se mais atuantes e exigentes, buscando produtos e serviços que atendam plenamente a suas atividades. Com isso, as empresas estão sendo obrigadas a reestruturar seus processos, visando a redução de custos e melhoria de desempenho operacional. A terceirização acaba por ser considerada uma ferramenta estratégica para gerir o negócio de forma mais barata, garantindo maior rentabilidade para a empresa (SILVA; SILUK, 2008). Além disso, grandes corporações brasileiras que visam o aumento de sua produtividade têm optado por utilizar a prática de terceirização, podendo assim focar em sua atividade principal e, com isso, aumentar sua competitividade em comparação a seus concorrentes (FREITAS, 2009).

Ao avaliar as indústrias farmacêuticas veterinárias instaladas no país, verifica-se que boa parte delas utiliza a terceirização como elemento do seu processo fabril com o objetivo principal de redução de custos. Tal objetivo torna os processos mais ágeis, flexíveis e adequados à realidade atual (VALÉCIO, 2016). 
Avaliação do impacto de desvios de qualidade em uma indústria farmacêutica veterinária na terceirização de processos produtivos

A terceirização da produção de medicamentos veterinários possui uma série de vantagens, a maior delas de ordem financeira. Em contrapartida, tem como desvantagem os riscos relacionados à manutenção da qualidade do produto. Isso pode ser verificado pela alta incidência de desvios ou não conformidades ocorridas no processo produtivo de forma geral nos últimos anos. Estudos demonstram que os custos relacionados a falhas que ocorrem antes do produto chegar ao cliente podem alcançar até $30 \%$ do faturamento anual de uma organização (CARVALHO; PALADINI, 2012).

Atualmente, as empresas estão inseridas em um cenário em que a qualidade é considerada vantagem competitiva e garantia de confiabilidade, podendo ser alcançada por meio de menores índices de não conformidades associadas à produção de medicamentos (SANTIN; CAVALCANTI, 2004; YU; PARK, HONG, 2017). É de extrema importância uma análise mais profunda, começando pela identificação de não conformidades e falhas, verificação de seus efeitos e determinação de sua causa raiz e, a partir daí a criação de ações efetivas e específicas para evitar potenciais recorrências (RATH; MARTINEZ-MEJIA; SCHRODER, 2015).

Assim, este trabalho tem como objetivo, por meio de um estudo de caso, analisar as perdas relacionadas aos desvios de qualidade em uma empresa do segmento farmacêutico veterinário durante a fabricação de produtos em empresas terceirizadas. Tal análise parte da avaliação das causas raiz determinantes dos desvios e verificação das fragilidades da empresa terceira.

Dada a importância do tema e os custos envolvidos nos processos produtivos, espera-se com o trabalho gerar contribuições teóricas e gerenciais, uma vez que as análises propostas e resultados obtidos podem criar possibilidades para implementação de melhorias que visam mudanças nos processos produtivos estabelecidos, incluindo terceirização, diminuindo a incidência de desvios de qualidade, reduzindo as perdas financeiras e contribuindo para otimização e manutenção da qualidade. 
Avaliação do impacto de desvios de qualidade em uma indústria farmacêutica veterinária na terceirização de processos produtivos

\section{REVISÃO DA LITERATURA}

O surgimento das indústrias farmacêuticas na Europa e nos Estados Unidos ocorreu no final do século 19, início do século 20. A partir da Segunda Guerra Mundial houve o início da produção em escala industrial na produção de penicilina pela Pfizer, uma importante empresa farmacêutica multinacional, o que evitou a morte de milhares de pessoas, sendo considerada um marco das maiores contribuições da indústria farmacêutica para a terapêutica (SIQUEIRA; CALIXTO, 2008).

A indústria farmacêutica no Brasil teve seu início e desenvolvimento entre 1890 e 1950, tardio quando comparado aos países europeus, com forte relação com a instituição de práticas de saúde pública, visando o combate de doenças infecciosas e o estabelecimento de pesquisa básica e aplicada (CONFEDERAÇÃO NACIONAL DO RAMO QUÍMICO, 2015).

Historicamente no âmbito mundial, devido às repercussões causadas pelo efeito teratogênico (malformação de fetos) causados pela droga talidomida na década de 1960, ocorreu um salto nas legislações para desenvolvimento de novas drogas. Como parte das normas exigidas pela Organização Mundial da Saúde (OMS), estabeleceu-se garantias de boas práticas de fabricação e teste de eficiência e segurança de novos medicamentos. Na maioria dos países, os processos de desenvolvimento, produção, estocagem, distribuição e vendas sofrem intervenções governamentais, tendo como base o órgão americano de regulamentação do setor (Food and Drug Administration - FDA) por ser a mais conhecido mundialmente e o mais restritivo (CAPANEMA; PALMEIRA FILHO, 2007).

Atualmente o setor de saúde no Brasil vive um momento de profundas transformações, passando por uma revolução e nova dinâmica nos negócios, tornando assim o mercado nacional um dos mais atraentes e promissores do mundo. Mesmo com sua complexidade, um aspecto marcante é o fato do país ser o único no mundo a contar com um sistema de saúde universal e gratuito conhecido como SUS (Sistema Único de Saúde). Os impostos pagos pelos brasileiros cobrem todo e qualquer tipo de atendimento e tratamento oferecidos pelo sistema. Isso beneficia a dinâmica do mercado da indústria farmacêutica, expandindo a produção pelo aumento das vendas de medicamentos (PWC, 2013). 
Avaliação do impacto de desvios de qualidade em uma indústria farmacêutica veterinária na terceirização de processos produtivos

A indústria fabricante de produtos farmacêuticos veterinários é conhecida como o segmento de saúde animal. Muitas empresas de produtos para saúde animal, em boa parte multinacionais, são também grandes empresas da indústria farmacêutica de saúde humana. $\mathrm{O}$ setor veterinário é considerado como uma complementariedade em relação ao farmacêutico tradicional devido à diluição dos elevados custos com pesquisa e desenvolvimento e a diversificação das atividades, aumentando assim a competividade das operações (CAPANEMA et al., 2007).

No Brasil o setor de agronegócio apresentou considerável crescimento econômico nos últimos anos, caracterizado pela utilização de tecnologias inovadoras e modernas técnicas de melhoramento da qualidade. Com o aumento das exportações, criadores de bovinos, suínos e ovinos têm procurado se adequar às exigências, garantindo melhor controle da qualidade de produto e/ou processos produtivos mais eficazes. Atrelado a isso, as empresas têm investido em novas tecnologias para o desenvolvimento de produtos que propiciem eficácia, lucratividade e também diminuam o impacto ambiental (CALARGE et al., 2007).

Nas últimas décadas, devido à maior necessidade de especialização e ao crescimento do setor, um forte movimento de fusões e aquisições vem ocorrendo. Um dos principais motivos é a necessidade de maiores recursos para atividades de pesquisa e desenvolvimento. A dificuldade de obtenção de novas formulações e a ineficiência dos produtos existentes no longo prazo contribuem para o aumento da necessidade de incremento de portfólio. Adicionalmente, a ampliação geográfica das áreas de atuação em função da dispersão da localização dos clientes, e a necessidade de uma boa estrutura de logística, são fatores que estimulam as empresas a adotar ações de fusões e aquisições. (OMOTE; SLUSZ, 2013).

\subsection{Qualidade na indústria farmacêutica veterinária}

Ao se falar em qualidade nas indústrias farmacêuticas veterinárias pode-se entender que é um passo indispensável ter uma gestão de qualidade estruturada e preparada para suprir as necessidades das organizações. A procura por novos métodos de qualidade fez com que o segmento crescesse e se desenvolvesse, pois não se tem vantagem competitiva se não houver uma gestão de qualidade efetiva (BISPO et al., 2015). 
Avaliação do impacto de desvios de qualidade em uma indústria farmacêutica veterinária na terceirização de processos produtivos

A garantia e o controle da qualidade nas indústrias têm por base normas, diretrizes e procedimentos legais diferentes de país para país, o que exige um esforço significativo para se atender e se adequar a tais requisitos (ROCHA; GALENDE, 2014).

Visando assegurar a qualidade, segurança, eficácia e credibilidade dos medicamentos junto ao mercado consumidor e atendimento dos padrões de qualidade exigidos pela legislação e normas regulamentadoras dos produtos finais, é de suma importância que as indústrias tenham um controle de qualidade efetivo e que otimizem seus processos, reduzindo tempo e desperdícios, padronizando procedimentos, qualidade do ambiente e dos insumos utilizados (AL-SHDAIFAT, 2015). De fato, nos últimos anos o controle de qualidade tornou-se a etapa mais importante de fabricação de um medicamento. Vale ressaltar que não existe um processo de gestão de qualidade pronto, cada empresa tem suas características e exibe soluções próprias que variam das demais, a despeito de todas atuarem no mesmo setor (ROCHA; GALENDE, 2014).

\subsection{Desvio ou não conformidade no processo produtivo da indústria farmacêutica veterinária}

Desvio ou não conformidade de qualidade está relacionada ao estado ou condição de um sistema, produto, serviço ou processo em que há mais características não conformes com a especificação, documentação, método e requisitos normatizados. É também atribuída a qualquer falha no atendimento e/ou expectativa do cliente (VIEIRA, 2016).

$\mathrm{Na}$ indústria farmacêutica veterinária, durante o processo produtivo, a qualidade é essencial. Medicamentos que não atendam às normas de Boas Práticas de Fabricação (BPF) e às legislações vigentes podem ocasionar problemas sérios, tanto para empresa - com a perda de credibilidade, cassação da licença de funcionamento e do registro do produto, retrabalhos como para o bem-estar dos animais, apresentando riscos sérios a sua saúde e prejudicando a proteção e segurança dos alimentos de origem animal (RATH; MARTINEZ-MEJIA; SCHRODER, 2015).

Além disso, problemas durante o processo produtivo podem contribuir para gerar não conformidades relacionadas ao teor dos princípios ativos dos medicamentos, presença de impurezas e produtos de degradação, alteração de viscosidade e dureza e ocorrência de 
Avaliação do impacto de desvios de qualidade em uma indústria farmacêutica veterinária na terceirização de processos produtivos

contaminação cruzada. Essas ocorrências geram problemas na eficácia e no propósito de aplicação do medicamento, contribuindo com a disseminação de doenças entre os animais, presença de resíduos nos alimentos acima dos limites mínimos permitidos por lei, apresentando ameaças à saúde dos animais tratados, como também à saúde dos consumidores de produtos derivados destes animais (RATH; MARTINEZ-MEJIA; SCHRODER, 2015).

\subsection{Desvios de qualidade}

Com a identificação de não conformidades, falhas ou desvios no processo, é de suma importância a determinação da causa raiz, ou seja, determinar o principal motivo que originou aquela falha e, a partir dele, tratar essas causas. Esse processo proporcionará ao sistema produtivo um ciclo de melhoria contínua, contribuindo para o aperfeiçoamento dos processos produtivos, aumento da produtividade, aumento da qualidade do produto e otimização do tempo (RATH; MARTINEZ-MEJIA; SCHRODER, 2015).

De acordo com as normas e legislações que regulamentam a produção de medicamentos do ramo de saúde animal, as empresas devem ter um sistema de qualidade robusto, capaz de investigar, classificar e determinar a causa raiz, e assim estabelecer ações preventivas e corretivas para não conformidades ou desvios que venham a ocorrer durante o processo. Para isso, as empresas detêm ferramentas de qualidade que as auxiliam como suporte para o levantamento de informações concretas e suficientes para uma boa investigação (RATH; MARTINEZ-MEJIA; SCHRODER, 2015).

A categorização dos desvios está sob competência da empresa responsável pelo medicamento que define a forma de organiza-los e como determinar uma maneira de avalialos, o que deve estar descrito em procedimentos internos. Com isso, é possível separá-los em grupos e assim facilitar a determinação da causa raiz e o estabelecimento de ações corretivas e preventivas mais eficazes (MAPA, 2016).

\subsection{Terceirização na indústria farmacêutica veterinária}

Ao analisar as indústrias farmacêuticas veterinárias instaladas no Brasil, percebe-se que boa parte delas utiliza a terceirização como parte do seu processo fabril, com o objetivo de redução de custos e elevação de produtividade, tornando os processos mais ágeis, flexíveis e 
Avaliação do impacto de desvios de qualidade em uma indústria farmacêutica veterinária na terceirização de processos produtivos

adequados à realidade atual. Em relação à responsabilidade final sobre o produto, ela fica a cargo do detentor de seu registro, independente se alguma etapa de produção, controle de qualidade ou armazenamento tenha sido efetuada por terceiros, ficando esses como responsáveis solidários com a contratante (VALÉCIO, 2016).

Em contrapartida, e de acordo com a legislação, é vetada a terceirização de todas as etapas de produção de um mesmo medicamento, salvo nos casos de fabricação que necessitem de tecnologias especiais para produção. Também não é permitida a produção de um mesmo produto em mais de uma terceirizada. Não é permitido terceirizar a produção ou parte dela de todos os produtos registrados pela empresa. Para se comercializar medicamentos no Brasil, é preciso ter sob sua responsabilidade todo processo produtivo de pelo menos um produto que esteja registrado em seu nome (VALÉCIO, 2016).

Levando em consideração as especificidades do setor farmacêutico veterinário, são considerados como benefícios da terceirização os seguintes fatores: melhoria da qualidade, aumento da competitividade e produtividade, redução de custos, maior flexibilidade e capacidade de adaptação às mudanças, liberação de espaço, desenvolvimento tecnológico dos itens terceirizados e redução dos níveis hierárquicos. Todavia, os fatores restritivos e os problemas encontrados estão atrelados à dificuldade de integração das culturas da empresa e do fornecedor, falta de envolvimento dos funcionários, não cumprimento das cláusulas contratuais acordadas, má escolha da empresa terceirizada, não conformidade do produto em relação à qualidade requerida pela empresa contratante, dependência excessiva, custo de demissões e problemas com sindicatos e, principalmente, o medo de exposição de informações sigilosas ou segredos tecnológicos da empresa. Todos esses fatores devem ser cuidadosamente analisados antes da escolha da empresa terceirizada (PERON E SÁ et al., 1998).

\section{METODOLOGIA}

O presente trabalho foi realizado por meio de estudo de caso de uma indústria farmacêutica do ramo de saúde animal. Trata-se de multinacional de grande porte com representatividade no mercado brasileiro e que terceiriza seu processo produtivo em múltiplas empresas terceiras. A empresa contratante analisada foi denominada empresa A. 
Avaliação do impacto de desvios de qualidade em uma indústria farmacêutica veterinária na terceirização de processos produtivos

A empresa foi escolhida para o caso devido a possibilidade de acesso aos dados necessários para a realização do trabalho e por ser boa representante do setor farmacêutico de saúde animal. Ela possui uma variedade de medicamentos, atingindo várias classes terapêuticas (biológicos antimicrobianos, terapêuticos, antiparasitários, suplementos nutricionais, linha para animais de companhia, e medicamentos para criação de peixes) e se caracteriza por ter parte da fabricação de seus produtos obtida por meio de empresas terceirizadas.

Estudos de caso são amplamente utilizados em construção de teorias. Segundo Yin (1994), estudos de casos são como experimentos de laboratório relacionados que servem como replicações, contrastes e extensões da teoria emergente. Porém, experimentos de laboratórios são fenômenos isolados de todo efeito externo, diferente de estudos de caso, que retratam situações do mundo real e envolvem o contexto em que estão inseridas. Eisenhardt e Graebner (2007) complementam, exaltando que a construção de teorias com base em estudos de caso é uma das melhores formas, se não a melhor, de se obter evidências de qualidade que sustentem as deduções propostas.

Realizou-se para o desenvolvimento do estudo de caso as seguintes etapas (EISENHARDT; GRAEBNER, 2007): escolha da empresa terceira para a realização da pesquisa; levantamento de dados por um período de seis meses; avaliação de lotes liberados e desvios ocorridos no período; avaliação das entregas considerando a solicitação da empresa contratante versus a entrega pela empresa contratada; conhecimento dos fluxo de processos após a detecção do desvio de qualidade e tempo de espera de aprovação dos lotes solicitados; verificação dos desvios de qualidade, suas respectivas causas raiz e tempo de finalização de investigação; classificação e quantificação das causas raiz dos desvios ocorridos no período; avaliação das ações corretivas e preventivas propostas para cada desvio; e identificação das deficiências no setor de qualidade da empresa terceira.

A empresa terceirizada foi denominada empresa B. Utilizou-se como critério para a escolha da empresa B sua importância financeira e a representatividade dos produtos que fabrica para empresa A, para quem entrega aproximadamente $500.000 \mathrm{~kg}$ de produto por mês, representando aproximadamente $61 \%$ do seu faturamento mensal. Além disso, verificou-se uma alta incidência de desvios de qualidade por parte da empresa $B$, possibilitando a realização de uma análise mais profunda e detalhada quando da avaliação destes desvios. 
Avaliação do impacto de desvios de qualidade em uma indústria farmacêutica veterinária na terceirização de processos produtivos

Devido ao fato da empresa A não estruturar estoques de segurança de seus produtos, a totalidade dos produtos fabricados pela empresa B precisa ser entregue dentro do prazo para conclusão do fechamento mensal. Isso demonstra que qualquer ocorrência de desvio que impacte a liberação dos lotes solicitados pela empresa A ocasionará danos financeiros a ela. Ao avaliar o histórico de fornecimento da empresa B, verificou-se que empresa A não possui qualquer avaliação do impacto financeiro dos desvios de qualidade em relação a sua contratada, o que também caracteriza uma oportunidade.

A coleta de dados foi realizada pelo cruzamento das informações de entrega de lotes solicitados pela empresa A versus o que foi entregue efetivamente pela empresa B, considerando-se lotes aprovados, lotes aprovados com desvio e tempo de espera de aprovação, desvios de qualidade (crítico, não-críticos e recorrentes), desvios em aberto que não haviam sido investigados, tempo de espera para investigação e finalização dos desvios, e retrabalhos que ocorreram dentro do prazo de seis meses de avaliação e que impactaram a liberação do produto para o mercado.

Os desvios de qualidade devem ser investigados e concluídos para que se tenha a certeza que o produto está de acordo com as normas e legislações e não comprometa a saúde dos animais que irão consumi-lo. Isso demanda tempo e pode comprometer a liberação do produto para comercialização dentro do prazo planejado.

O levantamento dos desvios ocorridos no período possibilitou a concomitante divisão das ações propostas, tais como manutenção de equipamentos da linha; revisão de procedimentos e documentação; reciclagem, orientação e treinamento de funcionários; e retrabalho de lotes. Isto possibilitou maior clareza no entendimento das deficiências e fraquezas da empresa $\mathrm{B}$ e garantiu a determinação de propostas de melhoria mais significativas com adequada destinação de investimentos.

\section{RESULTADOS E DISCUSSÕES}

Primeiramente foram avaliadas as entregas dos lotes solicitados pela empresa A. Posteriormente foram avaliados os lotes aprovados pela empresa A, seus lotes impactados por desvio, lotes em espera devido a investigação de desvio, e lotes rejeitados e retrabalhados. Por fim, foram avaliados os desvios de qualidade para o período, desvios aprovados (crítico e não- 
Avaliação do impacto de desvios de qualidade em uma indústria farmacêutica veterinária na terceirização de processos produtivos

crítico) de acordo com classificação prevista em procedimento da empresa B, desvios em aberto e desvios recorrentes.

A empresa A é responsável por avaliar a demanda de seus produtos no mercado, estabelecendo uma estimativa de vendas para aproximadamente 12 meses e planejar todo o fluxo de produção para entrega dos lotes, fazendo o acompanhamento mês a mês.

Essas informações são levantadas primeiramente pela área de marketing, em conjunto com a área de vendas, que estabelece quantidades a serem entregues por meio da avaliação de novos pedidos e de vendas passadas. Posteriormente são enviadas para a área de planejamento que considera o tempo desde a entrada das matérias-primas até a entrega do produto ao consumidor final.

A empresa A produz nove produtos na empresa B que possui uma linha de produção dedicada exclusivamente para manufatura dos materiais da empresa A. Não existem conflitos nem problemas por parte da empresa B na disponibilização de recursos para produção das demandas da empresa A.

Levantou-se o volume de produto solicitado pela empresa A, e o volume de produto entregue pela empresa B para o período avaliado, conforme indicado na Figura 1.

Figura 1- Volume de entrega de lotes

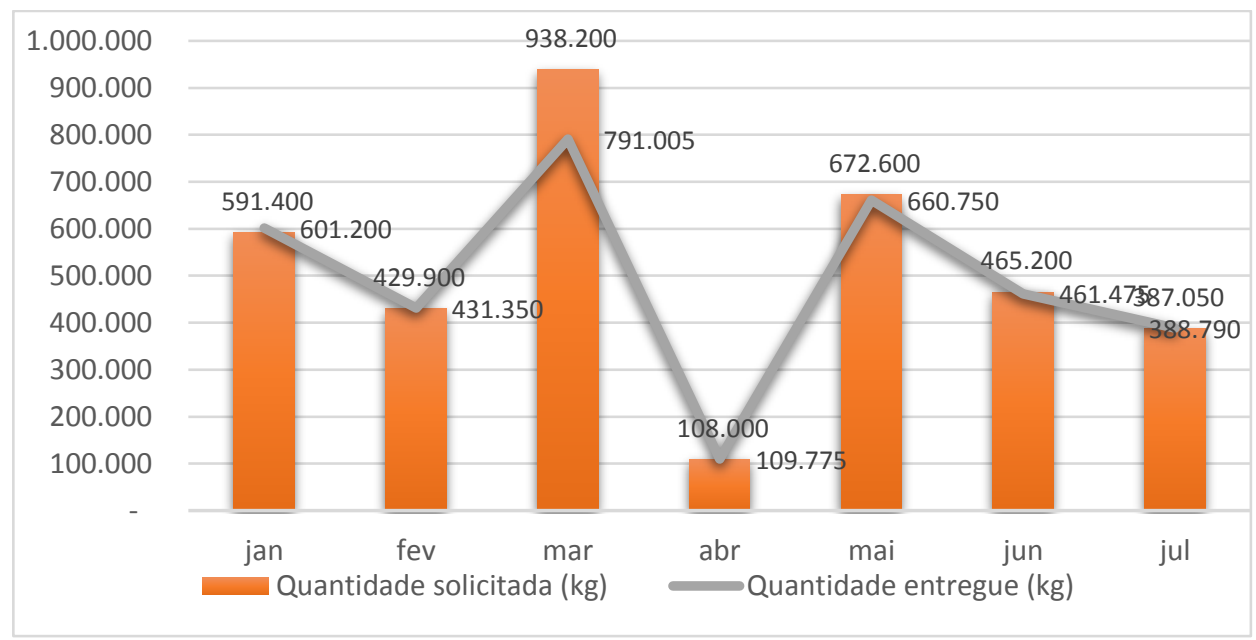

Fonte: Elaborado pelos autores. 
Avaliação do impacto de desvios de qualidade em uma indústria farmacêutica veterinária na terceirização de processos produtivos

Verifica-se a partir da análise da Figura 1 que existe uma correspondência entre a quantidade solicitada e quantidade entregue, ou seja, a empresa B manteve suas entregas de acordo com o desejado pela empresa A.

Apenas no mês de abril ocorreu uma diminuição na solicitação e entrega de lotes devido a indisponibilidade de matéria-prima para produção. Como a compra da matéria-prima é responsabilidade da empresa $\mathrm{A}$, ocorreram atrasos na entrega que impactaram diretamente a produção para o mês em questão.

Figura 2 - Aderência de entrega de produtos

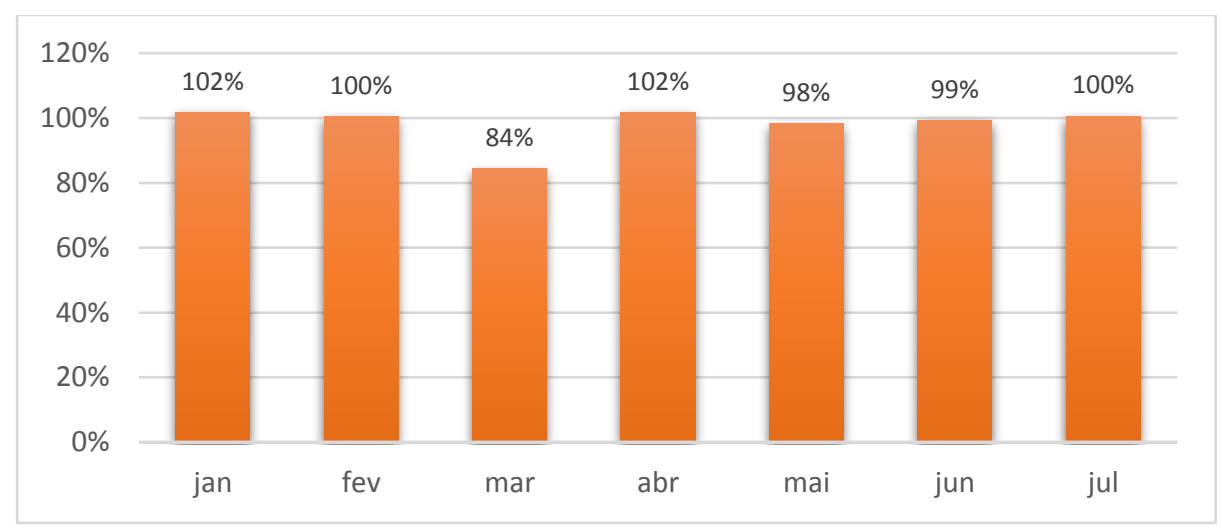

Fonte: Elaborado pelos autores.

A Figura 2 indica que nos meses de março, maio e junho as entregas foram inferiores ao solicitado. Entretanto, uma maior discrepância foi verificada no mês de março, quando ocorreu entrega 16\% inferior ao desejado. Tal redução na entrega causou impacto na empresa A, que não conseguiu suprir a quantidade de produtos para o mercado. Em função disso, as produções posteriores tiveram que ser reorganizadas para suprir a demanda.

Quando é verificada alguma inconsistência, a empresa A indica o desvio de qualidade e o lote em questão não pode ser expedido até avaliação do impacto para o produto. $\mathrm{O}$ fato de o lote estar retido por desvio não é considerado na entrega, ou seja, a empresa B recebe seu pagamento no momento em que o produto está entregue para a empresa $\mathrm{A}$, sem que seja considerado intercorrências durante o processo. 
Avaliação do impacto de desvios de qualidade em uma indústria farmacêutica veterinária na terceirização de processos produtivos

Após a expedição dos lotes por parte da empresa B, o produto se torna de responsabilidade da empresa A, que possui estrutura de garantia de qualidade que avalia toda documentação do lote, os processos e propõe a liberação final do produto para o mercado.

Após a avaliação da entrega de lotes contabilizou-se a quantidade de lotes aprovados/liberados para comercialização pela empresa A no período de análise desse estudo e o resultado obtido encontra-se na Figura 3.

Figura 3 - Número de lotes aprovados

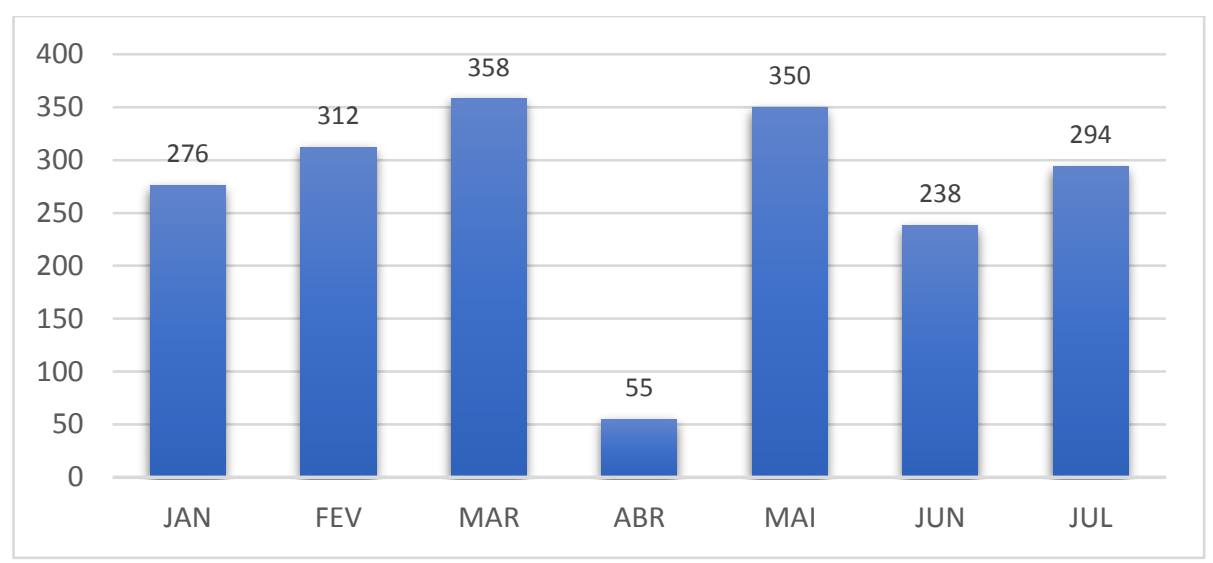

Fonte: Elaborado pelos autores.

Conforme evidenciado na entrega, verificou-se uma queda no número de lotes aprovados para o mês de abril devido a problemas de entrega de matéria-prima. Além disso, verificou-se a quantidade de lotes rejeitados e retrabalhados durante o período, que totalizaram 14 lotes entre maio e julho. A partir do número de lotes aprovados verificou-se quantos destes foram impactados por algum desvio ou falha de qualidade (Figura 4). 
Avaliação do impacto de desvios de qualidade em uma indústria farmacêutica veterinária na terceirização de processos produtivos

Figura 4 - Lotes liberados com desvio

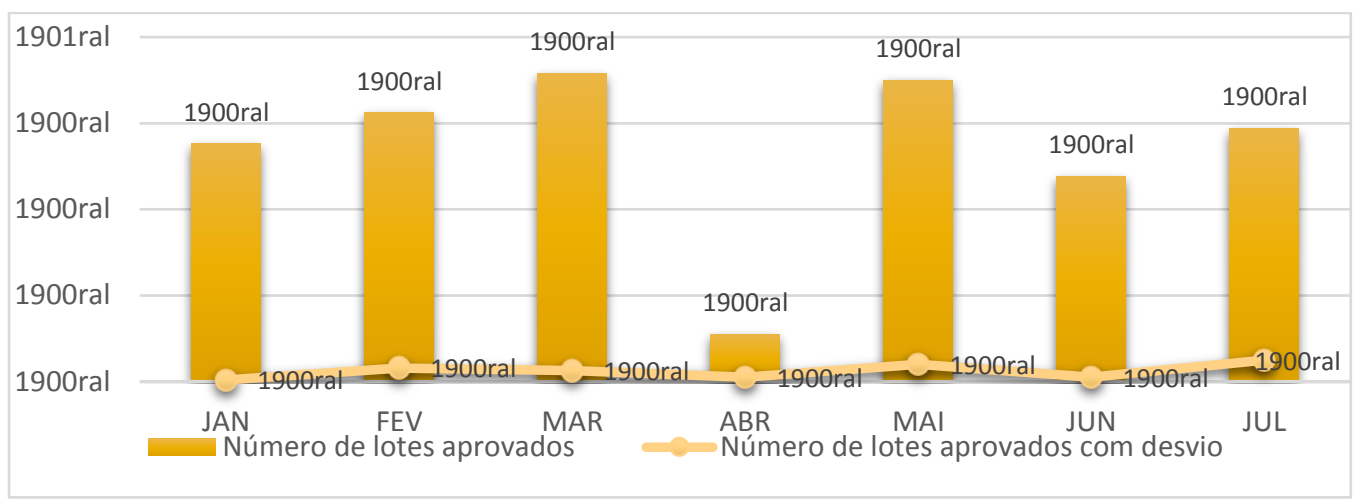

Fonte: Elaborado pelos autores.

Tem-se que dos lotes liberados ao se considerar o montante total, apenas uma pequena quantidade foi impactada por algum desvio ou falha. De qualquer maneira, deve-se levar em consideração a quantidade total de produto, uma vez que cada lote fabricado possui aproximadamente 120 sacos de $25 \mathrm{~kg}$. Além disso, cada lote ao ser impactado por um desvio de qualidade faz com que sua liberação seja postergada. Todo desvio é investigado, encaminhado e finalizado antes do lote ter aprovação final para comercialização pela empresa A.

Como próximo passo, levantou-se a quantidade de lotes que ficaram em espera de aprovação devido a finalização de investigação do desvio (Figura 5).

Figura 5 - Lotes em espera de aprovação devido a desvio

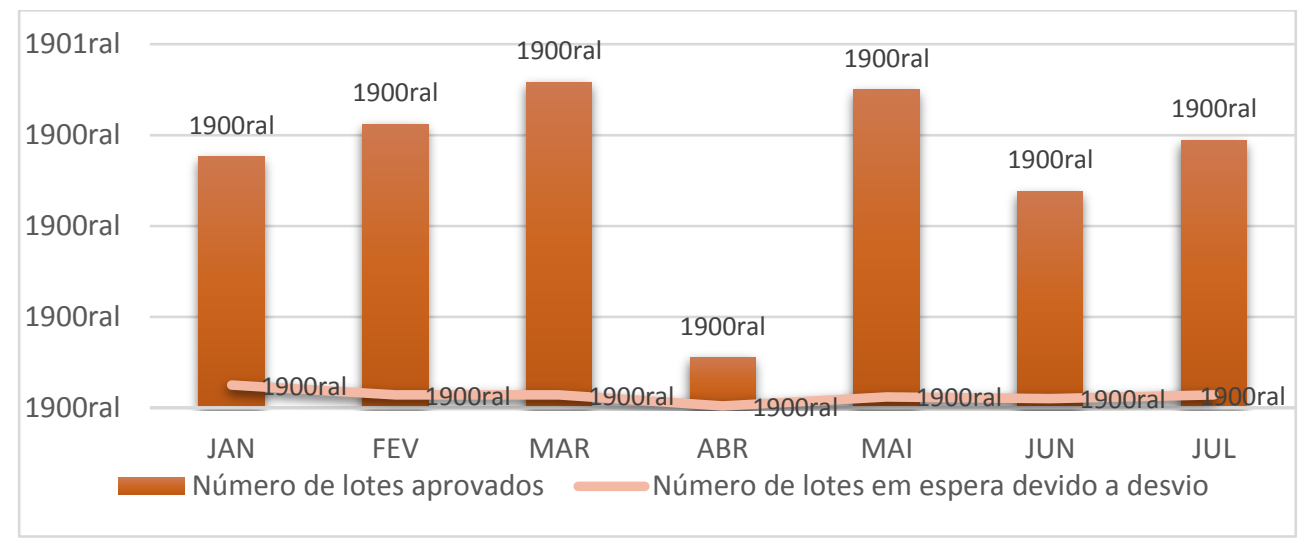

Fonte: Elaborado pelos autores.

GEPROS. Gestão da Produção, Operações e Sistemas, v. 14, nº 5, p. 215 - 238, 2019. 
Avaliação do impacto de desvios de qualidade em uma indústria farmacêutica veterinária na terceirização de processos produtivos

O impacto se mostra maior quando se verifica a quantidade de lotes que ficaram na espera de aprovação. Com isso foi estabelecido uma estimativa de tempo que esses lotes ficaram aguardando aprovação devido ao tratamento do desvio que os impactava (Figura 6).

Figura 6 - Tempo de espera de aprovação dos lotes envolvidos em desvio

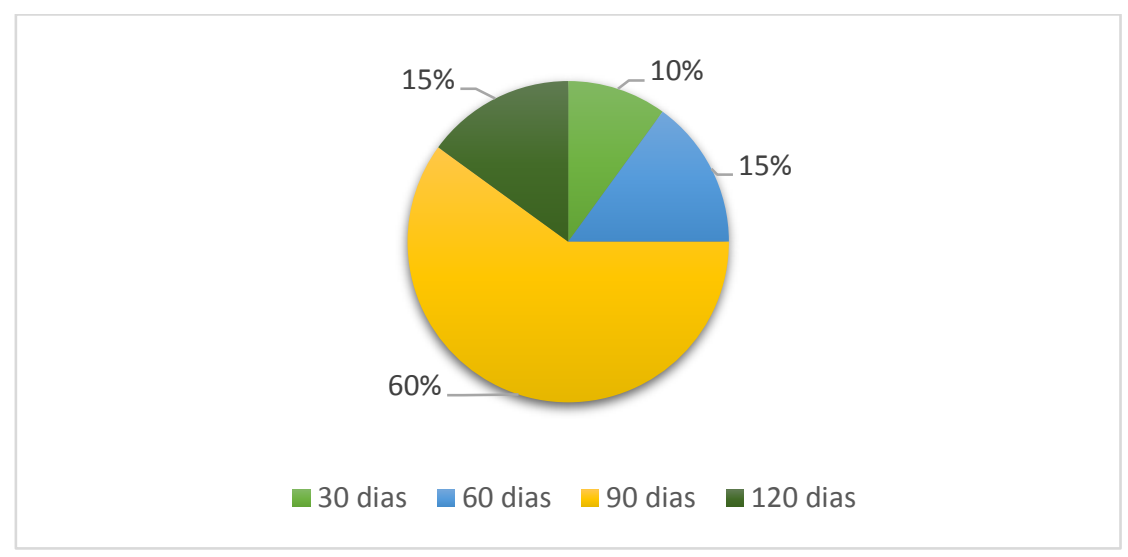

Fonte: Elaborado pelos autores.

Aproximadamente $60 \%$ dos lotes envolvidos em desvios tiveram um tempo total de aprovação de 90 dias, ou seja, os lotes ficaram parados no armazém aguardando liberação por quase 3 meses, afetando diretamente a entrega mensal de lotes para venda.

Analisando esses dados, pode-se concluir que a empresa B possui duas fragilidades, embora consiga corresponder a entrega da quantidade de lotes solicitados pela Empresa A: uma grande quantidade de lotes é entregue com desvios e não podem ser liberados; e o longo tempo de investigação e finalização dos desvios. Essas fragilidades não são consideradas pelas duas empresas. A empresa B é paga a partir do momento em que finaliza a fabricação dos produtos, sendo a responsabilidade, a partir deste ponto, passada para a empresa A.

Complementarmente, para melhor entendimento das fragilidades da empresa $\mathrm{B}$, foram abordados os desvios de qualidade ocorridos no período. Para o período de janeiro a julho de 2018 coletou-se os dados referentes aos desvios de qualidade críticos e recorrentes aprovados pela empresa A (Figura 7). 
Avaliação do impacto de desvios de qualidade em uma indústria farmacêutica veterinária na terceirização de processos produtivos

Figura 7- Desvios aprovados pela empresa A

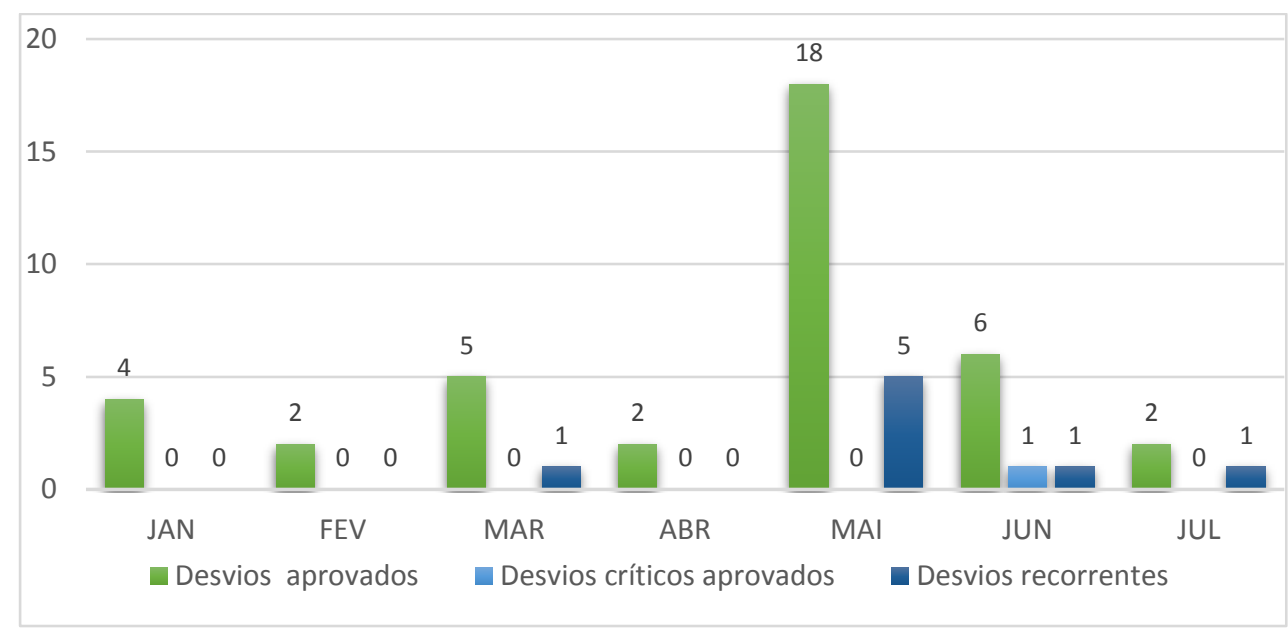

Fonte: Elaborado pelos autores.

Verificou-se para o período apenas um desvio crítico aprovado em junho. Este desvio foi relacionado a transcrição de dados na documentação do lote, em que o operador reimprimiu a página, sendo isso, pelas normas e regulamentos da indústria farmacêutica, considerado crítico. Entretanto, por ser uma falha de documentação e pontual, o desvio não afetou a liberação do produto.

Além disso, verificou-se para o mês de maio um aumento no número de desvios aprovados. Isso se deve à grande ocorrência de desvios e ao fato da equipe de qualidade da empresa $\mathrm{B}$ não ter dado conta de acompanhar todas as investigações necessárias. A empresa $\mathrm{A}$ disponibilizou sua equipe de qualidade que foi até a empresa B para ajudar nestas investigações e com isso conseguiram concluir um total de 18 desvios.

Outra tendência importante de ser avaliada são as recorrências de desvios, pois a partir delas são verificadas que as ações propostas da primeira ocorrência não foram eficazes, sendo necessário uma mudança na tratativa e que ações mais incisivas sejam colocadas em prática para que a mesma falha não volte a ocorrer. Para o mês de maio identificou-se um elevado número de desvios recorrentes, sendo aproximadamente $28 \%$ destes considerados como recorrentes. Concluiu-se que as ações corretivas propostas nos desvios anteriores não foram efetivas. 
Avaliação do impacto de desvios de qualidade em uma indústria farmacêutica veterinária na terceirização de processos produtivos

Dos desvios aprovados verificou-se também aqueles cujo prazo foi superior ao estabelecido em contrato. Também para o período avaliado verificou-se uma quantidade de desvios que ficaram em aberto, ou seja, a empresa B priorizou alguns desvios de acordo com a necessidade da empresa A. Certa quantidade de desvios ficou aberto aguardando investigação e finalização, demonstrado na Figura 8.

Figura 8 - Desvios de qualidade aprovados em atraso

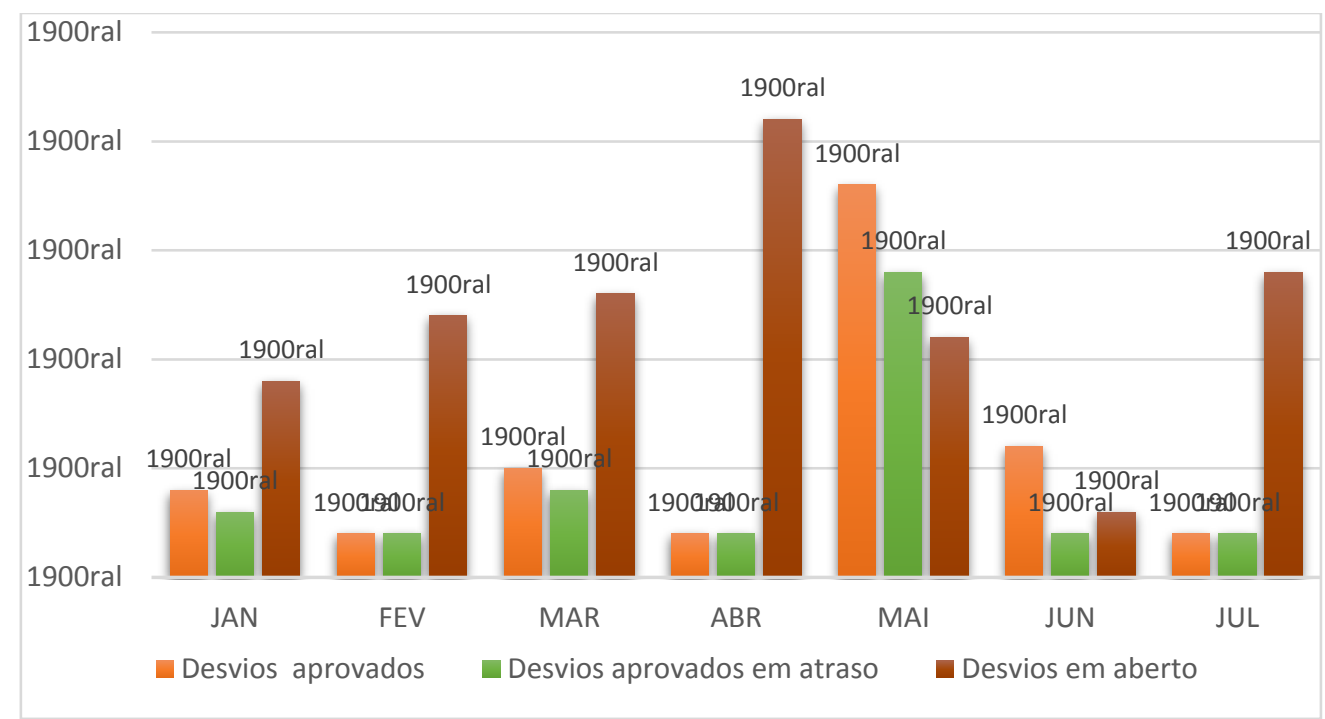

Fonte: Elaborado pelos autores.

Com os dados levantados, construiu-se um gráfico para melhor visualização das informações, conforme pode ser visto na Figura 9.

Figura 9 - Prazo de aprovação de desvios

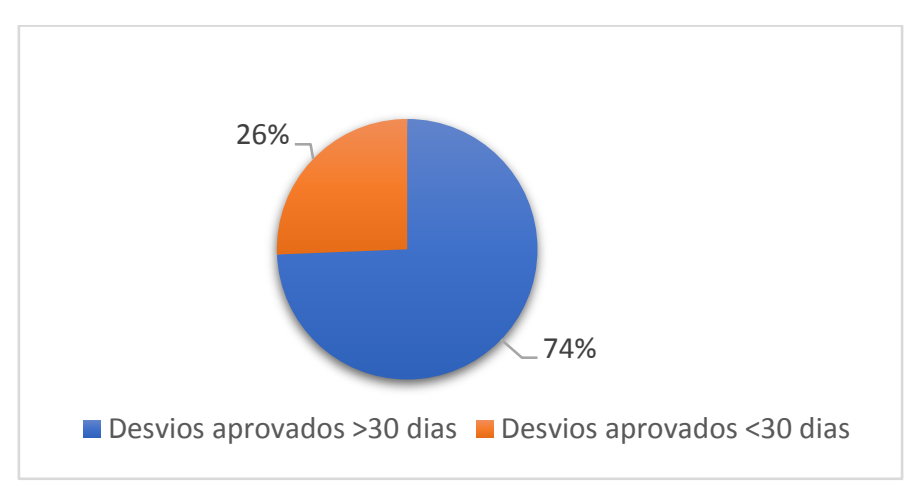

Fonte: Elaborado pelos autores.

GEPROS. Gestão da Produção, Operações e Sistemas, v. 14, nº 5, p. 215 - 238, 2019. 
Avaliação do impacto de desvios de qualidade em uma indústria farmacêutica veterinária na terceirização de processos produtivos

Aproximadamente $74 \%$ dos desvios aprovados foram investigados e finalizados em prazo superior a 30 dias, ou seja, apenas $26 \%$ dos desvios foram investigados e finalizados dentro do prazo estabelecido, afetando diretamente o fechamento mensal da empresa A.

Verificou-se que há grande dificuldade da empresa B em investigar e finalizar os desvios em conformidade com o prazo estabelecido. Esse fato acarreta a não liberação de lotes conforme planejado, afetando diretamente as vendas e o lucro da empresa A. Além disso, esse esforço para finalização dos desvios para a aprovação dos lotes não é considerado nos custos dos lotes entregues, ou seja, a empresa A se torna responsável pelo andamento e investigação dos desvios sem o apoio e preocupação da empresa B.

A partir da verificação dos desvios para o período foi possível dividi-los em grandes grupos em função de suas causas raiz. Essa divisão está demonstrada na Figura 10.

Figura 10 - Avaliação de Causa Raiz

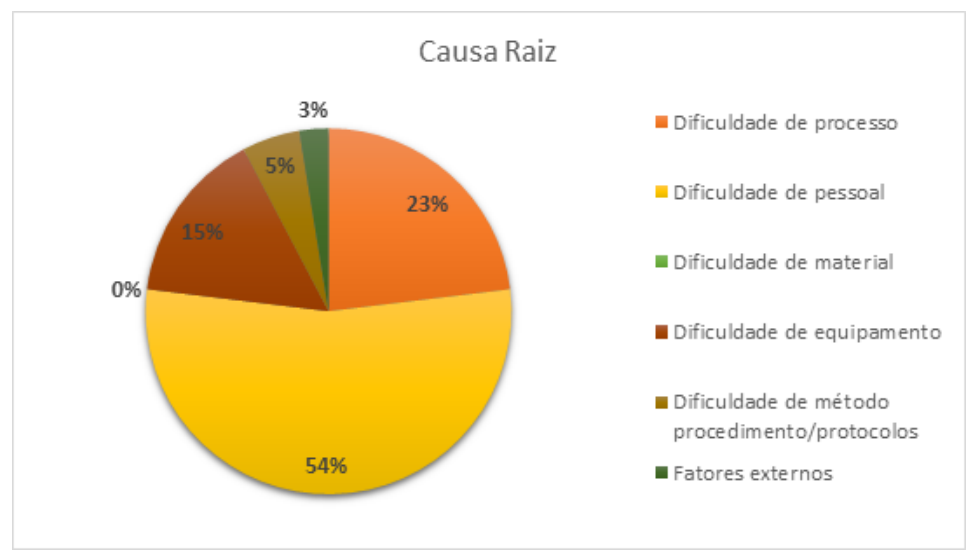

Fonte: Elaborado pelos autores.

A partir da avaliação dos resultados, tem-se que mais da metade dos desvios investigados $(54 \%)$ possuem como causa raiz dificuldade de pessoal, 24\% dificuldade de processo e $16 \%$ dificuldade de equipamento. Percebe-se uma enorme fragilidade de pessoal, ou seja, operadores envolvidos no processo de manufatura dos lotes. Fica evidente que os treinamentos ministrados para capacitação de pessoal não foram eficazes, havendo necessidade de verificação mais próxima dos desvios para que sejam tomadas iniciativas de reciclagem e treinamento das equipes por parte da empresa B. 
Avaliação do impacto de desvios de qualidade em uma indústria farmacêutica veterinária na terceirização de processos produtivos

O segundo maior grupo verificado foi a causa raiz dificuldade de processo. Isso pode ser atribuído ao fato da empresa B possuir produtos próprios e seus processos se diferenciarem dos processos exigidos pela empresa A, sem a devida documentação de procedimentos e tratativas.

A partir da avaliação dos resultados concluiu-se que a empresa B precisa estruturar melhor os seus processos e melhorar o treinamento e capacitação de seu pessoal, para assim reduzir a quantidade de desvio ocasionados por dificuldade de pessoal e processo.

Para uma melhor visibilidade das ações corretivas e preventivas propostas no tratamento dos desvios ocorridos, levantou-se quais foram as ações. Essas ações são revisão de procedimento, treinamento dos operadores, mudanças nas configurações dos equipamentos da linha e retrabalho dos lotes. A organização desses dados pode ser melhor observada na Figura 11 .

Figura 11 - Ações Corretivas e Preventivas propostas nos desvios

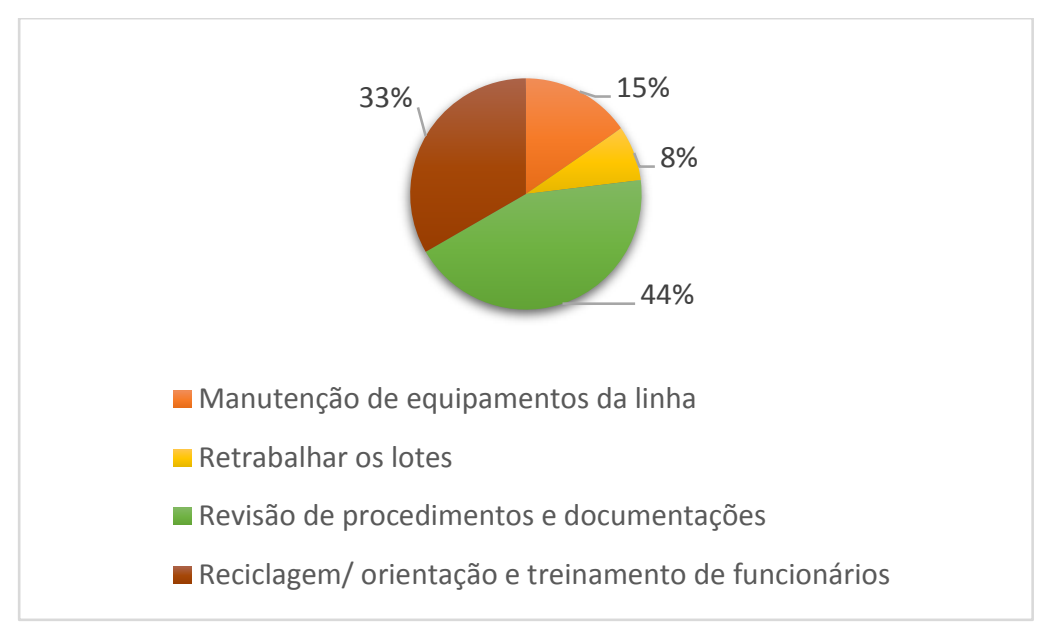

Fonte: Elaborado pelos autores.

A revisão de procedimentos e documentações esteve presente em aproximadamente $44 \%$ dos desvios. A causa deveu-se ao fato de toda estrutura ser baseada em procedimentos e qualquer mudança que ocorra deve ser documentada por meio de controle de alterações e revisões de procedimentos para que sirva como guia para de toda equipe da empresa B. 
Avaliação do impacto de desvios de qualidade em uma indústria farmacêutica veterinária na terceirização de processos produtivos

A segunda maior ação proposta estava atrelada à reciclagem/orientação e treinamento de funcionários, representando 33\%. Isso demonstrou que os funcionários envolvidos nos processos não estavam bem preparados e acabavam cometendo muitos erros. Com isso surgem ações para que eles sejam retreinados/reorientados.

É importante frisar que no contrato de prestação de serviços não há qualquer bonificação ou penalização financeira atrelados aos indicadores de qualidade ou tratamento de desvios de qualidade, ou seja, a empresa B apenas recebe pela quantidade de lotes entregues, não importando a qualidade dos mesmos. O cenário atual demonstra que a empresa A desconhece os custos envolvidos com os desvios de qualidade, e por esse motivo não interfere diretamente para promoção de mudanças.

De uma maneira geral, identificar as não conformidades e suas causas raiz possibilita a ação corretiva e preventiva gerando resultados que permitem redução de custos, aumento de qualidade e vantagem competitiva conforme preconizado pela literatura (RATH; MARTINEZMEJIA; SCHRODER, 2015; CAPANEMA; PALMEIRA FILHO, 2007; BISPO et al., 2015; ROCHA; GALENDE, 2014; VIEIRA, 2016).

Com isso, a terceirização dos processos produtivos acaba por exigir atenção das empresas contratantes, uma vez que estão de certa forma delegando à contratada vários dos cuidados e controles necessários para se garantir a qualidade, a identificação e tratamento das não conformidades (PERON E SÁ et al., 1998; VALÉCIO, 2016).

\section{CONCLUSÃO}

Este artigo teve como objetivo a realização de um estudo de caso para a análise das perdas relacionadas aos desvios de qualidade em uma empresa do segmento farmacêutico veterinário durante a fabricação de produtos em empresa terceirizada. Alguns critérios foram adotados e escolheu-se para avaliação uma empresa terceira de grande representatividade financeira para empresa em estudo.

Tanto em termos teóricos e gerenciais, este trabalho traz à luz os desafios relacionados a garantia de qualidade e a identificação e tratamento de não conformidades. Apresenta também as fragilidades decorrentes da terceirização de processos produtivos neste contexto, procurando 
Avaliação do impacto de desvios de qualidade em uma indústria farmacêutica veterinária na terceirização de processos produtivos

endereçar e estruturar formas de ação para identificação, correção e mitigação de recorrências das não conformidades ocorridas no processo produtivo.

Em vista disso, a análise baseou-se na avaliação das questões de entrega de produto, ocorrência e recorrência de desvios, causas raiz determinadas, ações corretivas realizadas, tempo de espera de aprovação dos lotes fabricados e tempo de investigação. Essa avaliação possibilitou a identificação das fragilidades do sistema de qualidade da empresa terceira.

Verificou-se enorme dificuldade de estruturação dos processos de qualidade por parte da empresa terceira, além de uma capacitação de pessoal ineficiente. Essas duas fragilidades são responsáveis pela alta incidência no número de desvios que impactam a qualidade do produto final.

A empresa terceira não consegue acompanhar os numerosos fluxos de investigação, não cumprindo com o prazo estabelecido em contrato. Considerável parcela de desvios é finalizada em atraso, dificultando a entrega dos lotes e impactando diretamente as vendas da empresa contratante. Vale ressaltar que a empresa contratante não consegue estabelecer um estoque de segurança devido à falta de disponibilidade de capacidade da linha produtiva.

Supõe-se que o fator principal nesta discussão está atrelado às fragilidades relacionadas ao contrato de serviços que não contempla, em termos financeiros, os desvios de qualidade, ou seja, a empresa terceira recebe apenas por cumprir com a entrega da quantidade dos lotes estipulados. A qualidade em que esses lotes são entregues não são previstos no contrato. Além disso, por não existir uma ferramenta de controle destes gastos com os desvios de qualidade, a empresa contratante desconhece os mesmos, e por desconhecê-los acaba não interferindo nesses processos.

É perceptível a necessidade de controle dos índices de qualidade por parte da empresa contratante. É perceptível também que por não ser questionada, a empresa terceira continua cumprindo com a entrega dos lotes solicitados sem se preocupar com a tendência do aumento do número de desvios que vem ocorrendo com o passar dos meses. Uma mudança nesse sentido só será verificada caso a empresa contratada seja prejudicada financeiramente, com punições e multas em caso de desvios de qualidade. Além disso, todas essas questões de qualidade verificadas pelo estudo devem ser descritas e contempladas de forma clara no contrato comercial, gerando um maior comprometimento por parte da empresa terceira. 
Avaliação do impacto de desvios de qualidade em uma indústria farmacêutica veterinária na terceirização de processos produtivos

As limitações do trabalho estão principalmente ligadas ao fato de terem sidos analisadas somente uma empresa contratante e uma contratada. Mesmo estas sendo representativas em seus setores de atividade, sugere-se como pesquisas futuras novos estudos de processos produtivos e terceirização em outras empresas farmacêuticas veterinárias nacionais e internacionais.

\section{Referências}

AL-SHDAIFAT, E. A. Implementation of total quality management in hospitals. Journal of Taibah University Medical Sciences, v. 10, n. 4, p. 461-466, 2015.

BISPO, L. Um estudo sobre as boas práticas de fabricação na indústria de medicamentos veterinários. São Paulo: Interface Tecnológica, 2015.

BRASIL, H. A empresa e a estratégia da terceirização. Revista de Administração de Empresa, v. 33, n. 2, p. 6-11, 1993.

CALARGE, F. et al. Aplicação do sistema de gestão da qualidade BPF (boas práticas de fabricação) na indústria de produtos farmacêuticos veterinários. Gestão e Produção, v.14, n.2, p.379-392, 2007.

CAPANEMA, L. X. L.; PALMEIRA FILHO, P. L. Indústria Farmacêutica Brasileira: Reflexões sobre sua estrutura e potencial de Investimentos. BNDS biblioteca Digital, Rio de Janeiro, 2007.

CAPANEMA, M. Panorama da indústria farmacêutica veterinária. BNDS Biblioteca Digital. Rio de Janeiro, 2007.

CARVALHO, M.; PALADINI, N. Gestão da Qualidade: Teoria e Casos. 2 Ed. Rio de Janeiro: Elsevier, 2012.

CONFEDERAÇÃO NACIONAL DO RAMO QUÍMICO. Panorama Indústria Farmacêutica. Publicação da CNQ-CUT, 2015.

EISENHARDT, K. M.; GRAEBNER, M. E. Theory building from cases: opportunities and challenges. Academy of Management Journal, v. 50, n. 1, p. 25-32, 2007.

FERNANDES, M. Informe setorial: Elaborado pelo Departamento de Produtos e intermediários Químicos e Farmacêuticos da Área Industrial. BNDS Biblioteca Digital, n. 27, 2013. 
Avaliação do impacto de desvios de qualidade em uma indústria farmacêutica veterinária na terceirização de processos produtivos

FREITAS, G. A Terceirização como ferramenta de gestão. Rio de Janeiro: Universidade Cândido Mendes, 2009.

MAPA, MINISTÉRIO DA AGRICULTURA, PECUÁRIA E ABASTECIMENTO. Legislação relacionada aos produtos de uso veterinário. BINAGRI. Brasília, Brasil, 2012.

OMOTE, H.; SLUSZ, Z. Prospecção de mercado visando P\&D para medicamentos veterinários para bovinocultura no Brasil. In: SIMPÓSIO INTERNACIONAL DE INOVAÇÃO TECNOLÓGICA. Anais... São Paulo, 2013.

PERON E SÁ, M. Terceirização no processamento final da Indústria Farmacêutica e Veterinária. Revista de Administração Contemporânea, v.2, n.2, p. 85-101, 1998.

PWC, Pricewaterhouse Coopers do Brasil. O setor Farmacêutico no Brasil. Panorama de mercado e tendências, $2013 . \quad$ Disponível em:http://www.pwc.com.br/pt_BR/br/publicacoes/setoresatividade/assets/saude/pharma13.pdf. Acesso em: 06 de maio de 2018.

RATH, S.; MARTINEZ-MEJIA, M. J.; SCHRODER, C. H. K. Considerations and practical implications of the guide for validation and analytical quality control of drugs in feed and veterinary drugs. Química Nova, v. 38, n. 5, p. 697-708, 2015.

ROCHA, T.; GALENDE, S. A importância do controle da qualidade na indústria farmacêutica. Revista Uningá Review, v. 20, n.2, p. 97-103, 2014.

SANTIN, M.; CAVALCANTI, O. Qualificação de fornecedores na indústria farmacêutica. Infarma, v.16, p. 11-12, 2004.

SIDAN. Sindicato Nacional da Indústria de Produtos para Saúde Animal. Anuário da indústria de produtos para saúde animal. 2018. Disponível em: http://www.sindan.org.br/anuario2018/. Acesso em 04 de maio de 2018.

SILVA, R.; SILUK, J. Terceirização: O Outsourcing como ferramenta estratégica. Trabalho de graduação. 82f. 2008. (Graduação em administração) - Unifra, Santa Maria, RS, 2008.

SIQUEIRA, J.; CALIXTO, J. Desenvolvimento de medicamentos no Brasil: Desafios. Universidade Federal de Santa Catarina. Florianópolis, SC, Brasil, 2008. Disponível em: http://www.gmbahia.ufba.br/index.php/gmbahia/article/view/269. Acesso em 04 de maio de 2018.

VALÉCIO, M. Terceirização da produção de medicamentos pode mudar. 2016. Disponível em: $\quad$ http://www.ictq.com.br/industria-farmaceutica/592-terceirizacao-da-producao-demedicamentos-pode-mudar. Acesso em 04 de maio de 2018.

VIEIRA, S. Estatística para a qualidade. 3 ed., São Paulo: Elsevier, 2016 
Avaliação do impacto de desvios de qualidade em uma indústria farmacêutica veterinária na terceirização de processos produtivos

YIN, R. K. Case study research: design and methods. $2^{\text {a }}$ ed. California: Sage, 1994.

YU, G. J.; PARK, M., HONG, K. H. A strategy perspective on total quality management.

Total Quality Management \& Business Excellence, 2017. Disponível em: https://www.tandfonline.com/doi/abs/10.1080/14783363.2017.1412256. Acesso em 04 de maio de 2018 